\title{
SoundSurfers: Developing a high-quality and empowering youth program
}

\author{
Jen Hesnan and Eoin Dolan \\ Jen.hesnan@techspace.ie and \\ eoin.dolan@foroige.ie
}

\section{Abstract}

SoundSurfers is a youth-led program of Foróige Ireland that provides a safe, dynamic and creative environment for young people aged from ten to eighteen years to empower themselves through music technology, practice and public performance. This article analyses young people's experiences of SoundSurfers within the context of recent research on effective youth programs. It demonstrates how the program engages young people from disadvantaged backgrounds and describes how national education organisations such as Camara Education Ireland and its TechSpace program can successfully equip skilled youth workers for this work. By fostering a diverse community of participants supported by skilled youth workers, young people can develop mutual respect and share common interests through peer-supported activities. The authors illustrate how offering mainstream creative provision enables a process that builds interdependence and empathy in young people. The SoundSurfers interagency approach is also highlighted to emphasise the positive opportunities and outcomes that can arise from this approach.

\section{Introduction}

In this article, we use the Foróige SoundSurfers youth music environment to explore our youth development work. Using Seymour's (2012) framework of good practice for youth development organisations, we identify key factors in our current work and demonstrate some of the positive outcomes and challenges that arise for youth participants and youth workers in Irish-based youth work environments. This article will focus specifically on how digital music technologies and creativity can complement youth development practice and empower young people to do the same.

\section{What is SoundSurfers?}

SoundSurfers is a Foróige youth development program. Foróige is Ireland's leading youth development organisation, with an ethos of empowering young people and 
enriching communities. SoundSurfers enacts the Foróige ethos through the provision of a safe, dynamic and creative environment for young people aged from ten to eighteen years, where they can explore their own, and discover shared, music interests in an open and relaxed atmosphere. We endeavour to engage a diversity of young people from disadvantaged backgrounds who are at risk of civic marginalization, such as young people with disabilities, from diverse social and cultural backgrounds, and in the social care and juvenile justice system. Individuals are engaged in interest-based activities and creative projects within a non-directed, interdependent and informal drop-in youth café space or Foróige Youth Club. Staff who run the SoundSurfers environments maintain key working relationships with targeted youth development agencies through an interdependent dual referral system. Specialised staff and volunteers are also present within the program space to support, respectfully engage with and actively listen to young people's social development needs and interests. Foróige is part of Ireland's national creative education network, TechSpace (see www.techspace.ie), which provides professional development training, creative tech support, digital technology skill development and a calendar of opportunities for youth development and education providers. We cofounded the SoundSurfers pilot drop-in programs across Foróige youth projects in Galway City, Ireland in 2012. Four years later, we have seen how the provision of a positive creative atmosphere can allow young people to develop an understanding of their own needs and how this understanding leads to an array of positive outcomes.

\section{What is the national TechSpace network?}

TechSpace is a national movement that aims to change the lives of young people in Ireland by becoming Ireland's leading creative technology support network for outcome-focused youth development. TechSpace, managed by the not-for-profit education organisation Camara Education Ireland, builds the capacity of youth organisations and schools to run creative digital media and Science, Technology, Engineering, Arts and Maths (STEAM) education programs. Through these programs, young people build 'creative confidence' (Kelley and Kelley 2013) and twenty-firstcentury skills (P21 Partnership for 21st Century Learning 2017), such as creativity, critical thinking, communication and collaboration - all vital for their successful futures. By engaging and supporting youth workers and teachers across Ireland, the TechSpace Central team aim to:

- inspire young people to use their interest in technology to become tomorrow's digital creators, inventors and makers, and not just consumers of technology

- train and support educators to confidently identify and adopt technologies within their pedagogy and youth development work

- support the growth of the TechSpace Network as a learning community of young people, youth workers, educators and volunteer mentors interested in enhancing youth development through ICT education.

Figure 1 maps the growing locations of the TechSpace network operating in the year 2016 in over sixty youth development sites across Ireland, known as hubs, satellites and starters. 


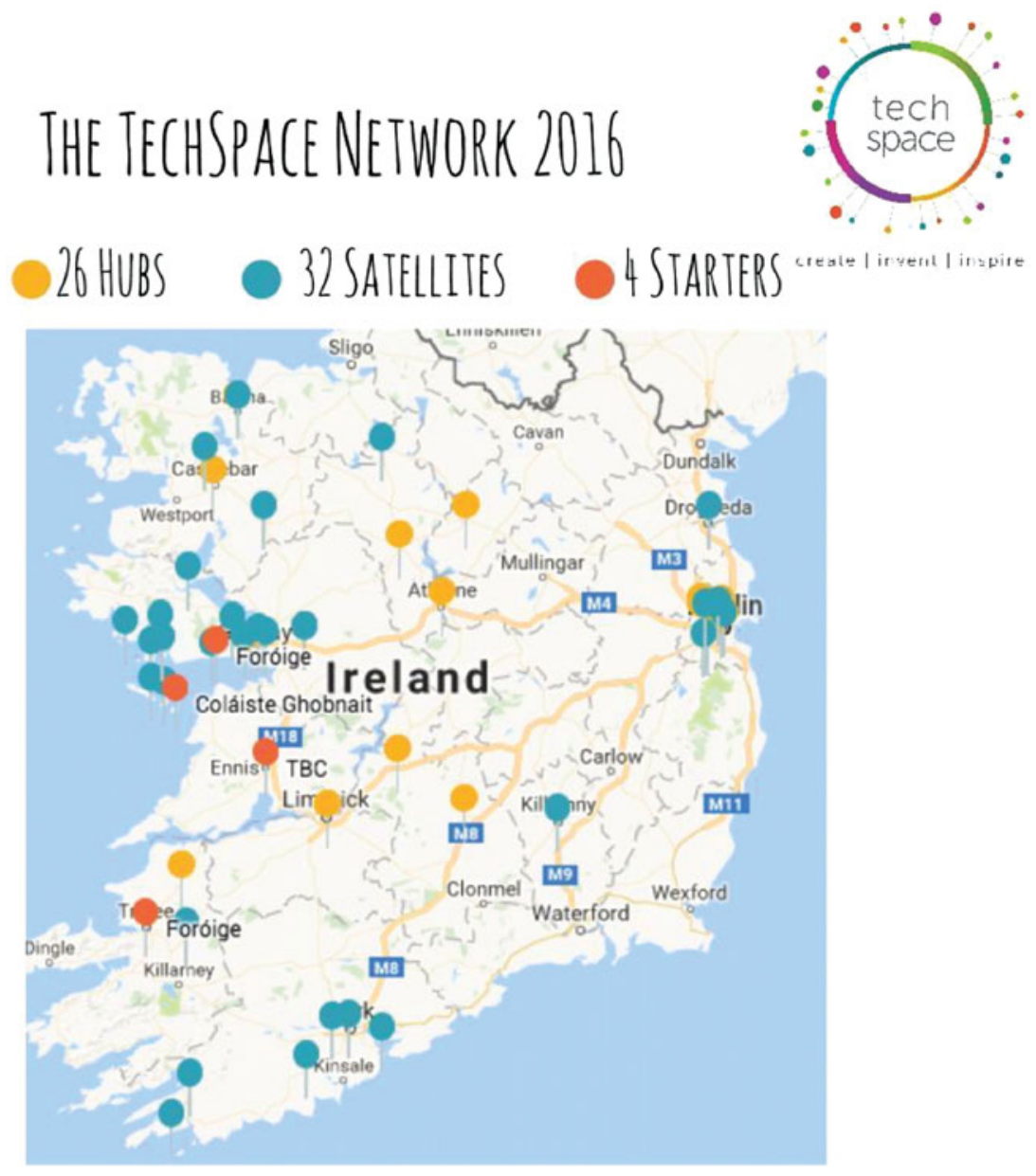

Figure 1

(Colour online) The TechSpace Network 2016.

A TechSpace-trained educator facilitates activities in Digital Media, STEAM and Creative Technologies through youth development principles with young people in a school or youth club. The TechSpace educator also becomes part of a National TechSpace Shared Learning Network, where they can avail of annual opportunities, Creative Tech Support and pathways to upskilling. TechSpace grew from The Computer Clubhouse Model (Kafai et al. 2009) in response to a fundamental need for young people across Ireland to gain access to constructivist engagement in creative technology. TechSpace's fundamental learning and practice principles in digital media have grown from the internationally recognised Adobe Youth Voices program (Adobe1 2017). By empowering youth workers in Foróige to deliver creative digital media projects, a need for a music-based digital media drop-in program was quickly realised in Galway, and SoundSurfers was formed. It was conceived of a place where young people could learn how to complement and share their musical interests by engaging with trained educators whist having access to 


\section{THE FORÓIGE PHILOSOPHY}

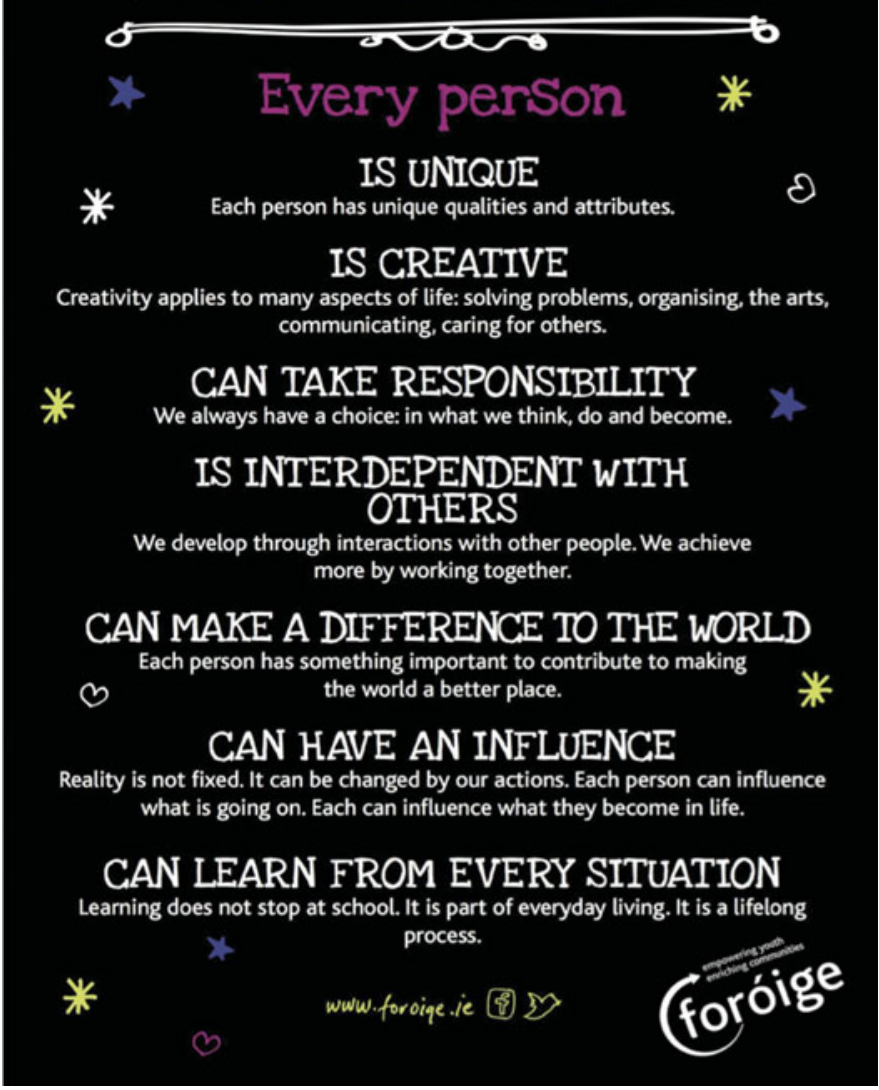

Figure 2

(Colour online) The Foróige philosophy.

modern technology and media equipment. The engagement in national networks such as TechSpace and Foróige has allowed young people to positively contribute to their micro and macro community structures by taking part in events to showcase their work.

\section{Ethical promotion and practice}

SoundSurfers has proven to be an invaluable catalyst in breaking down barriers and negative preconceptions. It has created an atmosphere where young people are both respectful and supportive of each other's diverse needs by fostering a sense of interdependence within the program. Indeed, empathy education underpins all of our work. We believe that empathy is fostered by the Foróige philosophy, shown in Figure 2, which underpins the work of Foróige youth workers. Foróige staff practise the Foróige philosophy in their work and in all of the youth development programs and spaces they offer to promote and fulfil the ethos of youth empowerment. We 
promote The Foróige philosophy in the ways we practice, encourage and promote music.

The SoundSurfers environment promotes an atmosphere of empowerment by encouraging staff and volunteers to entrust young people with power over their space and the content of an evening's drop-in. Staff endeavour to provide a safe, comfortable environment for young people to lead on creative activities that interest them. This is sometimes a lot easier said than done when working with vulnerable young people. Many staff and volunteers can be apprehensive about allowing young people to have full access to delicate equipment. We have found that by nurturing a trusting environment in a drop-in environment, young people will feel more comfortable about using the space while maintaining an atmosphere of respect. This practice aligns with the TechSpace model derived from the Computer Clubhouse. Ethical challenges that arise as a result of this open atmosphere can be treated by calling on young people's critical faculties. Staff and volunteers aim to include participants in creating a system to problem-solve to maintain and advance their environment of trust and empowerment.

Ensuring our programs and activities are resourced appropriately, enabling young people to attain the promoted outcomes (Seymour 2012: 42), has been one of the most challenging ethical promotion practices to achieve. Dedicated staff and a multi-agency approach have eased the financial pressure of delivering the program. However, with growing government cutbacks to the staffing of early intervention and youth-led programs in Ireland, we need to rely heavily on dedicated volunteers and funding through creative means such as applying for small grants to update equipment for the space, or training grants to ensure that volunteers are trained and given further opportunities. Despite funding pressures, paid and volunteer staff work tirelessly to maintain an ethically sound and reliable program environment in which young people are able to take part. We believe that the key activities we identify and discuss in this article contribute to young people developing a sense of the Foróige philosophy and SoundSurfers ethical values.

Case Study 1 demonstrates our approach in action. Young people are gifted with the responsibility to use the equipment as much as possible. If equipment gets damaged as a result of use, we endeavour to involve young people in every step of maintenance and working out solutions.

\section{Case study 1: Problem-solving with young people}

For a period of time, musical equipment was being damaged in the café. Young people, adult volunteers and staff were becoming increasingly frustrated by the situation and wanted to find a positive solution to the problem. After a group discussion, we ascertained that items were being damaged due to improper storage rather than malicious destruction. The group came together and built wooden storage units to keep and protect the expensive equipment. In this scenario, the problem was solved by young people and adult workers coming together to find a practical solution. The adults were not looking to play 'the blame game'; instead, they responded in a respectful and proactive manner. As a result, nobody felt singled out and everyone was satisfied with the process and outcome. 


\section{Partnerships and social networks}

TechSpace and Foróige work with a consortium of partners such as youth organisations, industries, government bodies and third-level education bodies to enhance collaborative learning and opportunities for young people. At a local level, youth workers connect with partner organisations in the community to support an interdependent dual referral relationship to ensure young people have access to a high level of service delivery. Young people are referred regularly to SoundSurfers activities by many different local community partners and targeted youth services. Equally, young people are often referred out by staff to different services in the community in order to meet their specific needs. An example of this practice in action can be seen in Case Study 2:

\section{Case study 2: An inter-agency approach}

Sarab ${ }^{1}$ is fourteen years old. She first became involved in SoundSurfers when she recorded a song in the studio facilities at her local youth café. Thereafter, Sarah became actively involved in the project and built a positive relationship with staff and volunteer leaders. After several months, Sarah disclosed to a staff member that she was feeling depressed and was experiencing serious stress in her day-today life. The staff member reassured Sarah, and told her that she would get the support she needed. With her permission, staff members contacted JIGSAW and made arrangements for Sarah to be introduced to a professional counsellor. Since the initial disclosure, Sarah has continued to be involved with SoundSurfers, as well as being provided with the additional mental health supports that JIGSAW has to offer.

Table 1 illustrates the unique strength and benefits of this inter-agency approach.

Working with so many agencies that can refer into SoundSurfers creates an interdependent community resource for young people. This inter-agency approach also enables young people to leave labels at the door. Young people who are within their originating targeted agency and who often feel labelled based on their personal circumstances or misfortunes are integrated into a specialised community of interest where these labels can be left behind. This community is characterised by youth-led youth work, using the best practice of youth work principles without focusing on the negative aspects of a young person's life. That is not to say that the challenges facing young people within a club can be ignored. On the contrary, the ethos of SoundSurfers is to embrace the challenges facing a young person, to be mindful and open when speaking to the young people. The Computer Clubhouse Model highlights the need for young people to feel safe and confident before they are ready to take on new opportunities: 'Even with all these options, youth won't take advantage of the opportunities unless they feel "safe" to try out new ideas. In many settings, youth are reluctant to do so, for fear of being judged or even ridiculed' (Kafai et al. 2009: 24).

Good practice in building partnerships and social networks is also about the kinds of relationships we build with young people and their families. It is important to develop an open and honest communication process with young people and their parents/guardians. Both guardian and youth worker must feel comfortable to speak about issues the young person is facing and the young person must be aware of this communication. This level of transparency and communication happens when a 
Table 1 Local SoundSurfers partnership examples and how they work.

Partnership/referral agencies

An Garda Síochána (Irish Police Service)

Health Service Executive Social Work Department

TUSLA - the child and family agency)

TUSLA - the School Completion Program

Autism response groups

Jigsaw - youth mental health service

Youth Work Ireland a national consortium of youth projects Garda Youth Diversion
Program

Local foster families and parents
Brief description of partnership

Community policing is a vital component of community life in Galway city and the surrounding suburbs. Members of An Garda Síochána regularly drop into SoundSurfers to build trust and relationships with the young people in a relaxed and positive environment. This approach is of particular importance to young people who are in some way involved in the juvenile justice system and who also attend SoundSurfers.

The Social Work department regularly refers young people into the SoundSurfers program who they identify as having a particular interest in music, audio and technology. As well, SoundSurfers staff are regularly in contact with social workers and, if they notice that a young person at risk has displayed any unusual behaviour, they can ring the social worker to follow up or check in.

TUSLA staff provide vital back-up support to the families of young people attending SoundSurfers. This support can greatly help young people and their families to overcome adversity and provide practical supports in their daily lives. SoundSurfers works with TUSLA referrals and equally refers into TUSLA services when necessary. Many Foróige staff work within a TUSLA context as part of their weekly post.

The main aim of the School Completion Program is to 'increase the numbers of young people staying in primary and second level school and in doing so improve the numbers of pupils who successfully complete the Senior Cycle, or the equivalent' (www.tusla.ie). Music practice can provide many opportunities for young people looking to remain in the education system. An example of this was witnessed in SoundSurfers recently, when a young person who was originally at risk of leaving school at sixteen went on to complete his leaving certificate so as to attain a diploma in music technology at third level. The young person recently expressed that his discovery and ongoing passion for sound engineering encouraged him to remain in school and look at career options into the future.

Local autism response groups have worked with Foróige by using the drop-in space out of hours for autism-specific youth clubs. As well, many of the facilitators in local autism groups are part of the TechSpace Network and regularly support young people to take part in wider opportunities such as SoundSurfers or the Creative Tech Fest. Over the past four years, we have noted many positive outcomes for all by actively including young people on the autistic spectrum.

Jigsaw is a youth mental health service that offers free counselling to young people aged from fifteen to twenty-five years. JIGSAW is situated next door to the Galway City Youth Café, where a weekly SoundSurfers session takes place. Counsellors can bring young people next door and introduce them to Foróige staff or volunteers.

SoundSurfer staff members have also used Jigsaw as a break-out space in the past during times of crisis for young people.

Youth Work Ireland stages an annual Youth Music Awards for young people. Those involved get a unique opportunity to perform and record their original compositions to a large audience. Young people who have started in SoundSurfers have performed at these national awards.

The Garda Youth Diversion Program engages young people who are linked to the criminal justice system. Many young people involved in this project find the music studio space in SoundSurfers to be a fulfilling and cathartic environment to express their life experiences.

Since its inception in 2013, SoundSurfers has continually supported young people who are in the care system. This partnership has provided a positive outlet for foster families to introduce teenagers in their care to the creative environment of music technology and practice. 
Table 1 Continued

\begin{tabular}{ll}
\hline $\begin{array}{l}\text { Partnership/referral } \\
\text { agencies }\end{array}$ & Brief description of partnership \\
\hline Big Brother, Big Sister & $\begin{array}{r}\text { The Big Brother Big Sister mentoring program has engaged with } \\
\text { SoundSurfers, where 'Big' and 'Little' matches have on an ongoing basis } \\
\text { attended sessions to explore their shared musical interests. } \\
\text { SoundSurfers facilitators have visited local schools to give talks and } \\
\text { information on the program to students and teachers. This partnership } \\
\text { has strengthened relationships and built lasting bonds. It has also } \\
\text { encouraged young people to generate a more positive outlook on their } \\
\text { school and education goals. }\end{array}$ \\
\hline
\end{tabular}

youth worker remains non-judgemental and supportive in their conversations with young person and parent.

\section{Case study 3: Calling for help}

Jack (thirteen) had been attending SoundSurfers for weeks, but did not seem interested in engaging in any of the creative projects and found it hard to relax in the space. Instead, he insisted on drawing his name on the walls in permanent marker, or in some cases breaking things. Despite the protests of youth workers and volunteers, Jack continued his destructive behaviour. Each week, a new version of his name could be found on walls in the bathroom or main room of the club. No matter how many times Jack was asked to stop or given an ultimatum of missing the next club, he continued to turn up and continued to draw on the walls. After four weeks of working with Jack, one of the youth workers told him that his parents would have to be informed. After failing to get through to his mother, the youth worker eventually spoke to his father over the phone. His father explained that it was no surprise to him his son had started to display challenging behaviour in a group setting. Jack's mother had recently been diagnosed with a terminal illness. The father was apologetic, and explained he hadn't had much time with supporting the family of eight siblings to dedicate time to Jack. It struck the youth worker after this conversation that the writing of the names on the wall had become Jack's way of calling for help. In this case, she asked Jack's father for suggestions about how best to support Jack and provide what he needed. The involvement of Jack's father instantly improved Jack's engagement levels and increased the youth worker's understanding of Jack's needs. He and his father turned up to the SoundSurfers drop-in the following week with paint rollers in hand to freshly paint the youth club walls and spent some time together out of the home.

This case study example highlights the benefits that can flow from using a transparent and non-judgemental approach to our work, in order to avoid blaming young people and seek the most appropriate way to understand and empathise with their world. In this case, the youth workers, with the help of Jack's father, were able to better understand the context of his behaviour and build a positive space for Jack to relax and develop.

\section{Community service}

The link to the TechSpace Network and the community-based ethos of local Foróige projects support young people to showcase their creative projects to local, national 


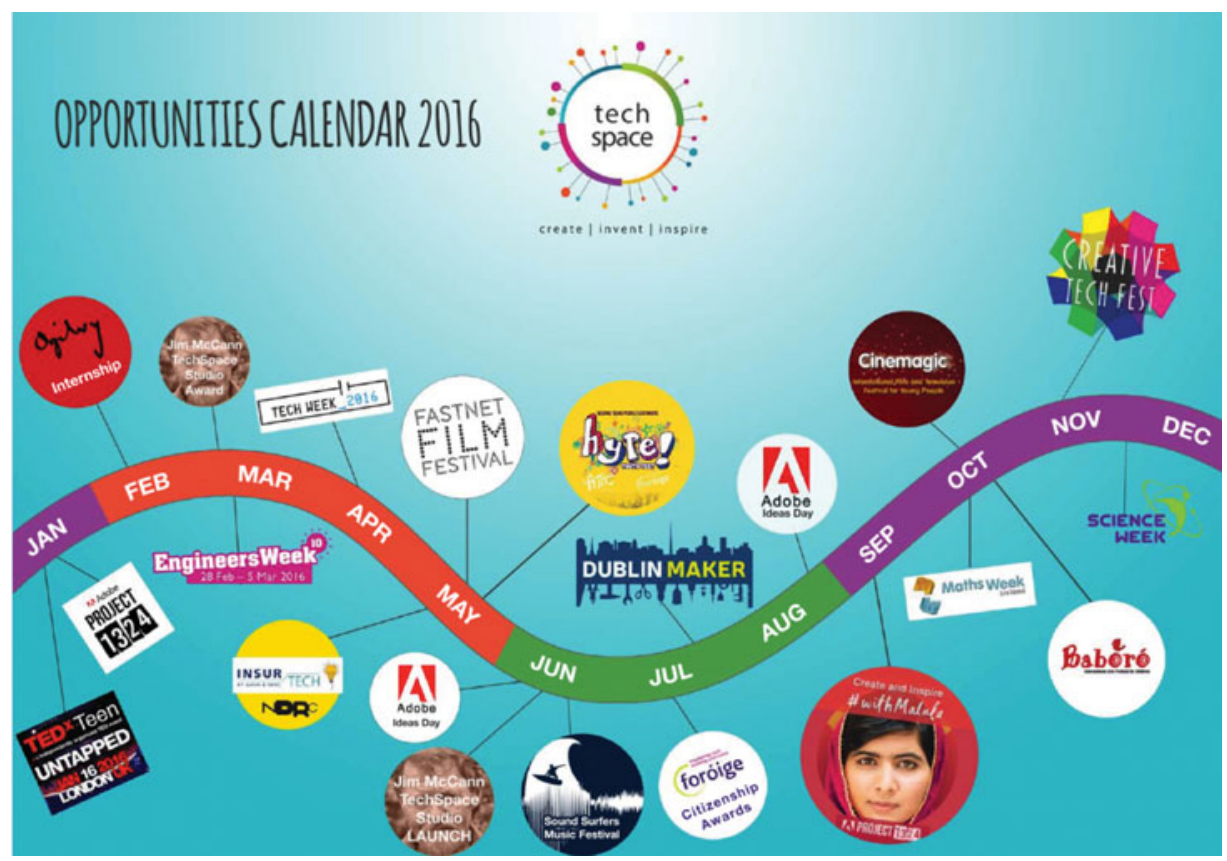

Figure 3

(Colour online) TechSpace opportunities calendar 2016.

and global audiences. By providing a safe incubation space for young people, their 'creative confidence' can be developed. Tom and David Kelley (2013: 8) describe the term 'creative confidence' as the need for everyone to realise their own creative abilities to contribute to the world by creating something new:

Creativity is much broader and more than what people typically consider the 'artistic fields'. We think of creativity as using your imagination to create something new in the world. Creativity comes into play wherever you have the opportunity to generate new ideas, solutions or approaches. And we believe everyone should have access to that resource.

SoundSurfers holds the building of creative confidence at its core. By remaining open to facilitate any youth-led project within the space, staff ensure that any young person's creative ideas can be fostered, whether music based or not. By harnessing positive local and global networks to celebrate the creativity of the participants, the opportunities for the young people are increased greatly. This approach creates a process whereby, once engaged in a project, young people can be facilitated to 'create with purpose' (Adobe2 2017) and express topics that are passionate to them through song, creative writing or digital exhibition.

In many cases over the course of the SoundSurfers projects in Foróige Galway, young people have created pieces of work that reflect what is important to them and have shared them in local venues. By engaging with the TechSpace annual calendar of opportunities (Figure 3), young people also have the opportunity to showcase their work or facilitate a workshop at a national level at events such as the Creative Tech Fest, which has taken place in Google's The Foundry venue in Dublin. 


\section{An inclusive ethos}

SoundSurfers actively supports and promotes an inclusive ethos. This is underpinned by a fundamental belief in youth interdependence and civic engagement in modern society. Rather than building a targeted program based solely on counteracting perceived negative lifestyle practices, staff and volunteers empower young people by reinforcing positive, personal and collective interests in a safe and encouraging environment. Inclusion is a natural result of our approach at Foróige. As previously noted, societal labels are left 'at the door', as young people actively participate and work together in a variety of different music and interest led projects.

Promoting and supporting youth interdependence or mutual reliance is a cornerstone of the SoundSurfers program. Creating music, live performances and digital media is commonly a collaborative and symbiotic process. Incorporating TechSpace-trained staff in digital media and STEAM activities into that space complements the music-based activities that are happening. This allows young people more options to work together, learning to trust, respect and rely on each other's unique skill set. All of this leads to an interdependent environment. An example of the interdependent environment in practice can be seen in Case Study 4.

\section{Case Study 4: Leave your labels}

John is fifteen years old. For many years, he has come into contact with the juvenile justice system for various minor crimes and misdemeanours. He was made aware of SoundSurfers through his local Foróige project worker, who knew John had a passionate interest in music. From the outset, John was keen to use the studio facilities at SoundSurfers to record his own original compositions. However, John had no technical expertise to operate the various different microphones and sound engineering equipment.

Mary, who is 16 and on the autism spectrum, has a keen interest in all aspects of music technology. Through the support of a SoundSurfers staff member, Mary learned how to operate the equipment in the recording studio and record songs for other young people. When they met and started to work together, the labels of 'juvenile' and 'autistic' were irrelevant. Both John and Mary saw themselves and each other as 'performing artist' and 'sound engineer'. They became interdependent with each other in a truly positive and meaningful way through a shared passion for music practice.

If John had been placed in a juvenile offenders' group, he would never have met Mary; similarly, if Mary had been segregated into an autistic-specific group, she would never have met John. By focusing on music and creativity, SoundSurfers enables diverse young people to be recognised for their knowledge, skills and abilities, and not their labels.

\section{Leadership and decision-making}

SoundSurfers promotes youth leadership and decision-making through music practice by giving agency and responsibility to participants. However, young people who engage in the program are often not eager to become leaders instantly. Some young people can find the idea of making important decisions as soon as they walk in the door of a club or drop-in space to be daunting. We have noted that when youth workers and volunteers are encouraged to greet all of the young people as 
they come in the door, a young person will immediately be made to feel welcome in the space. Introducing yourself, offering to show them the space, asking them about their interests or offering a kind gesture such as making a cup of tea can help a young person to feel at ease before they are ready to engage in a creative project.

We have observed that by creating an inclusive ethos first, and by having an approachable attitude without adults dominating the space, young people naturally begin to take ownership over the governance and content of the activities, exploring projects together and strengthening the sense of community among youth participants. This is illustrative of the shifting power paradigms that can occur when a youth program is committed to ensuring that young people feel empowered to create based on their own interests. Ensuring that the projects created are based on what each young person is interested in allows young people to develop their creative confidence.

\section{Case Study 5: One step at a time}

Tom is fourteen years old. For most of his life, he has been in state care. Tom has moved around a lot in his life, and has found it difficult to make friends. When Tom first stepped into SoundSurfers, he was greeted with a warm welcome by everyone in the group. He was given a tour of the space and provided with information on the different activities that were available to him - such as sound production, open mic nights, guitar lessons and so on. Over the coming weeks and months, Tom was given the space and time to settle into his new surroundings. Initially, Tom didn't engage in any of the structured SoundSurfers activities. He instead spent the time relaxing in the chill-out area, making new friends and enjoying the overall musical atmosphere of the space. Approximately three months after his initial engagement, Tom and a few of his new-found friends decided to set up a 'Battle of the Bands' evening of live music. Volunteers and staff supported Tom and the young people on their new venture and the event was a great success. Tom has since gone on to coordinate many other live music nights with the team supporting him every step of the way.

From his initial engagement, Tom was not obliged to engage in structured activities. He was able to freely decide where and when he felt ready to participate. Tom was also given the agency to lead a group of young people in creating something - a Battle of the Bands - that was relevant to him and his group of friends.

\section{Learning and development}

A fundamental element to the success of SoundSurfers is the development of oneto-one relationships of worth between staff, volunteers and youth. Positive peer relationships are formed among youth themselves. Youth participants are empowered to develop creative projects with peers through music production, digital media technology and the creative arts. Although the social development and educational needs of each young person are taken into consideration, the medium of creative practice and music acts as a catalyst for young people to develop in their own time. This empowerment process allows a collective of young people to share skills, knowledge and opinions to national and international networks. Young people from a variety of backgrounds are given the opportunity to demonstrate empathy education with their peers by challenging socially imposed labels. Participants also 
gain transferable skills by having access to trained staff, equipment and volunteers. Young people are provided with an array of experiences and career opportunities through TechSpace and local Foróige networks.

\section{Case Study 6: Building the CV}

Gabriel joined a TechSpace club at the age of fourteen in 2013. At the time he had just received his Autism Spectrum Disorder diagnosis. With this new late diagnosis, naturally his parents were worried about his ability to complete mainstream education, his ability to make friends and how this was going to shape his future. Gabriel was suffering from severe anxiety and he was struggling to cope when he joined the club. He settled in with his peers in TechSpace by using his special interest of coding and working with them on an interactive multimedia exhibition entitled Exhibition Awesome. Through the National Youth Council of Ireland, this exhibition was launched at the Galway Arts Centre and also ran in The Shed, a local art gallery. Gabriel was one of the lead artists on this project, and used his time at the exhibition to explain the complexities of the technology in the exhibits. Because of his work on this exhibition, he was asked, at the age of sixteen, to speak at an International UNESCO Symposium to youth workers and academics in Dublin. In 2015, he was engaged in an app design idea where he worked with a group in SoundSurfers and became an international finalist in the Adobe Youth Voices Awards. Gabriel's love of music led him to learn sound engineering and because he helped out in many open mic nights in his local SoundSurfers, he was asked to assist at a local event for the Galway Capital of Culture 2020 bid in town. In 2016, Gabriel graduated from secondary school and completed the leaving certificate year. He also applied for a scholarship for university and when doing so realized, looking back, that his résumé was packed with extra-curricular achievements since 2013.

This personal story of creative engagement, and local and international achievements, creates a picture of how initiatives such as TechSpace and SoundSurfers can complement the learning and development of any young person. However, more importantly for Gabriel, a sense of acceptance and peer support allowed him the confidence to pursue his projects and overcome his anxiety following his diagnosis.

\section{Conclusion}

Preliminary observations and direct feedback from participants suggest that the youth development principles practised at SoundSurfers create a greater sense of empathy, compassion and understanding for its participants. Young people have been engaging in arts venues, community and cultural institutions locally, nationally and internationally. They have created digital media exhibitions and performances, facilitated peer workshops and film screenings, and even produced their own local pop-up festivals. Positive outcomes for young people have been far reaching, and they encourage us to continue to pursue support for the program to grow both nationally and internationally. In order for this program to continue to deliver high-quality early intervention, it is important to maintain the integrity of core best-practice principles for youth work as outlined above. We aim to continue to deliver our program of activities and, as we consider the development of SoundSurfers internationally, we believe that maintaining its integrity is key to providing multifaceted outcomes for effective youth development. 


\section{Endnote}

1 The names of individual youth case studies within this article have been changed for the protection of the young people involved.

\section{References}

P21 Partnership for 21st Century Learning 2017. 'Our work', http://www.p21.org/ our-work/p21-framework.

Kelley D. and Kelley T. 2013. Creative confidence: Unleashing the creative potential within us all. New York: Collins.

Seymour K. 2012. Good practice principles for youth development organisations, 2nd ed. Brisbane: Key Centre for Ethics, Law, Justice and Governance, Griffith University.

Kafai Y., Peppler K. and Chapman R. 2009. The Computer Clubhouse: Constructionism and creativity in youth communities. New York: Teachers College Press.

Adobe1 2017. 'Creating social change through the power of digital storytelling', http://www.adobe.com/ie/corporate-responsibility/education/adobe-youth-voices.

Adobe2 2017. 'Adobe Youth Voices', http://www.adobeyouthvoices.com. 